\title{
Treatment Outcomes and Determinants of Eclampsia and Severe Preeclampsia Among Pregnant Women Admitted to Selected Tertiary Hospitals in Ethiopia: A Cohort Study
}

\author{
Abduro Godana' \\ Dula Dessalegn $\mathbb{1}^{2}$ \\ Fuad Adem ' \\ Dumessa Edessa (iD \\ 'Department of Clinical Pharmacy, \\ College of Health and Medical Sciences, \\ Haramaya University, Harar, Ethiopia; \\ ${ }^{2}$ Department of Pharmacy, Institute of \\ Health, Jimma University, Jimma, Ethiopia
}

Background: Eclampsia contributes to $12 \%$ of all maternal deaths worldwide during pregnancy. Again, women with severe preeclampsia and eclampsia had a three to 25 -fold increased risk of severe complications. Therefore, this study was aimed to determine treatment outcomes and determinants of eclampsia and severe preeclampsia among pregnant women admitted to selected tertiary hospitals.

Methods: A prospective cohort study was conducted on 217 women with eclampsia or severe preeclampsia from April 1 to October 30, 2019. Data were collected from patients' chart, questionnaire-based interviews at baseline and telephone interviews during follow-up. Then, the collected data were entered into EpiData 3.1 and exported to SPSS 21.0 for final analysis. Kaplan-Meier (log rank test) and Cox regression were employed to compare baseline survival experience and to adjust for the predictors of clinical outcomes, respectively.

Results: Of 217 women, $80.2 \%$ of them developed maternal complications, while nine (4.2\%) women died. Determinant factors of maternal complications were linked with eclampsia case (AHR: 1.98; 95\%CI: 1.28-3.06; $P=0.002$ ), lack of ANC follow-up (AHR: 1.75; 95\%CI: $1.22-2.51 ; P=0.002$ ), presence of maternal leukocytosis (AHR: $1.53 ; 95 \% \mathrm{CI}$ : $1.12-2.09 ; P=0.008$ ), elevated serum creatinine (AHR: $1.51 ; 95 \% \mathrm{CI}: 1.05-2.17 ; P=0.02$ ), and maternal age of $20-35$ years (AHR: $0.61 ; 95 \% \mathrm{CI}$ : $0.41-0.90 ; P=0.01$ ).

Conclusion: Despite improved survival of women with preeclampsia/eclampsia, different complications that they experienced remained serious problems. We suggest strategies that comprise frequent ANC follow-up and check-up for women with leukocytosis and kidney impairment so as to optimally prevent and treat eclampsia and preeclampsia during pregnancy.

Keywords: eclampsia, severe preeclampsia, treatment outcome, survival analysis, Ethiopia

\section{Introduction}

Hypertensive disorders of pregnancy (HDP) when measured appropriately, are defined as a diastolic blood pressure (DBP) of $90 \mathrm{mmHg}$ or higher or systolic blood pressure (SBP) of $140 \mathrm{mmHg}$ or higher after 20 weeks of gestation in a woman with previously normal blood pressure. ${ }^{1}$ They are classified into six subtypes, of which severe preeclampsia accounted for $39.96 \%$, followed by the other types including gestational hypertension $(31.40 \%)$, mild preeclampsia $(15.13 \%)$, chronic hypertension in pregnancy $(6.00 \%)$, preeclampsia superimposed
Correspondence: Abduro Godana Email gelgobona@gmail.com 
on chronic hypertension (3.68\%), and eclampsia $(0.89 \%){ }^{2}$ According to the World Health Organization (WHO), secondary analysis of multi-country survey on maternal and newborn health, incidences of preeclampsia and eclampsia cases were $2.16 \%$ and $0.28 \%$, respectively. Maternal nearmiss cases were eight times more frequent in women with preeclampsia, and this can be increased by far to up to 60fold higher frequency in women with eclampsia. ${ }^{3}$

About $99 \%$ of maternal deaths were occurring in lowand middle-income countries given that many public hospitals have limited access to antenatal care (ANC) follow-up and neonatal intensive care. This maternal or perinatal mortality is highly attributable to eclampsia rather than preeclampsia. ${ }^{4}$ In line with this, the nationwide prevalence on hypertensive disorders of pregnancy indicated $6.07 \%$ and just over $90 \%$ (5.47\%) of this figure accounted for preeclampsia/eclampsia. ${ }^{5}$ Again, in Jimma University Medical Center, severe preeclampsia was the most common hypertensive disorder of pregnancy, attributed to $51.9 \%$, while the proportion of eclampsia was $23.4 \%{ }^{6}$

Disease burden due to preeclampsia/eclampsia and the Ethiopian health system's response showed preeclampsia/ eclampsia complicated $1.2 \%$ of all institutional deliveries. ${ }^{7}$ The exact pathogenesis of preeclampsia or eclampsia is not clearly stated but the possible risk factors were nulliparity, maternal age $<20$ years and $>40$ years, multiple gestation, preeclampsia in previous pregnancy, chronic hypertension or renal disease, diabetes mellitus, elevated BMI, and phospholipid syndrome, and family history of the case. ${ }^{8}$

Current strategies for prevention of preeclampsia, which is the precursor of eclampsia, can be broadly classified as antenatal surveillance, modification of lifestyle, nutritional supplementation, and pharmacological therapy. Treatment is largely symptomatic and antihypertensive drugs are mandatory for very high blood pressure (BP $\geq 160 / 110 \mathrm{~mm} \mathrm{Hg}$ ). Although termination of pregnancy is the only definitive treatment for preeclampsia or eclampsia, the optimal timing for delivery of women with severe preeclampsia before 32 to 34 weeks gestation remains a dilemma. ${ }^{4}$ Currently, standard care for women with severe preeclampsia and/or eclampsia is to use an anticonvulsant to prevent or control the immediate seizure (fit) and continue maintenance treatment to prevent further seizure recurrence; the preferred anticonvulsant is magnesium sulphate $\left(\mathrm{MgSO}_{4}\right){ }^{9}$

Even though magnesium sulphate has been included into the National Drug List of Ethiopia and was being used for prevention or treatment of severe preeclampsia and eclamptic seizures for decades, there were only a few retrospective studies done to assess the impact of the drug on maternal outcomes as a country in general and at selected hospitals in particular. So that by considering prospective study design and hospitals encompassing a wider and diverse group of patients, the study hoped to fill an information gap about maternal outcomes of anticonvulsant use and may also serve as an input for further research.

\section{Methods}

\section{Study Settings, Design and Participants}

The study was conducted in Jimma University Medical Center (JUMC) and Hiwot Fana Specialized University Hospital (HFSUH), Ethiopia. JUMC which is found in the southwest of Ethiopia is one of the oldest public hospitals in the country and provides almost all major types of medical services such as clinical services including delivery and maternal and child health services for approximately 9000 inpatients and 80,000 outpatients a year from its catchment population of about 15 million. ${ }^{10}$ HFSUH which is found in Harari regional state is located $526 \mathrm{~km}$ to the east of Addis Ababa and services over 2000 patients per day.

A prospective cohort study design was conducted from April 1 to October 30, 2019. During this period, pregnant women admitted to maternity wards of both hospitals who fulfilled eligibility criteria were enrolled to the study.

\section{Eligibility Criteria}

We considered all pregnant women with confirmed diagnosis of eclampsia or severe preeclampsia. Again, those pregnant women who were managed with magnesium sulphate or other anticonvulsant for prophylaxis or treatment of seizures were also recruited for the study. However, women with convulsions and/or coma secondary to other medical illnesses such as epilepsy, cerebral malaria, and stroke were excluded. Women who developed complications before admission to maternity wards of these hospitals were also excluded from the study.

\section{Sample Size and Sampling Procedure}

The sample size was determined using the single proportion formula, where the $P$-value was taken from the previous study that showed the prevalence of maternal complication of eclampsia of $14.3 \%{ }^{11}$ Since the total 
pregnant women admitted to maternity wards of both hospitals was less than 10,000, reduction formula was applied and after $10 \%$ nonresponse considered, the total sample size of 217 were proportionally recruited from both hospitals by convenience sampling technique.

\section{Data Collection Instrument and Procedure}

The data collection tool was a semi-structured questionnaire which was developed after reviewing relevant literature. The questionnaire included information such as maternal sociodemographic and obstetric characteristics, laboratory findings, risk factors of eclampsia or severe preeclampsia, and treatment outcome variables.

In the process of data acquisition, baseline data pertaining to patent's sociodemographic factors, personal and/or family history of chronic medical illness and maternal parity, gestational age, social history and seizure episode were obtained by interviewing the women or their care givers (ie, for unconscious women). In addition, information including route of delivery, onset and duration of labour, and baseline measurements such as vital signs, laboratory values and medication(s) were retrieved from patents' medical records using a semi-structured data abstraction questionnaire. Besides, treatment outcome data such as maternal complications, survival status, and seizure recurrence were abstracted from the medical charts of the patients, whereas outcome data after their discharge from the hospitals were collected by interviewing them through telephone calls. Cohorts of women with severe preeclampsia and eclampsia were followed from hospital admission to the first 42 days postdelivery. The time at which each event occurred was recorded throughout the follow-up period. The patients were followed-up from their maternity ward admission to date of delivery. In addition, they were observed for a maximum of six weeks (42 days) starting from the postpartum period.

\section{Data Quality Assurance}

The data collection tool was prepared in an English version and the interview part of the tool was translated to local languages. It was translated back to English to confirm consistency and appropriateness of the translation. A pretest was conducted on $5 \%$ of the total sample size and appropriate changes to the tool were made. Three data collectors (one pharmacist, one clinical nurse, and one midwife) and two supervisors (a general practitioner and a medical intern) were hired at each setting. Two days of training on the data collection tool and general procedures was provided and questionnaires were reviewed for completeness and consistency on a daily basis by supervisors and principal investigator.

\section{Definitions and measurement of outcome variables}

Maternal complications and mortality were the primary clinical outcomes of the study. Occurrence of at least a complication such as aspiration pneumonia, severe anemia, acute kidney injury, HELLP syndrome, puerperal sepsis, disseminated intravascular coagulation, pulmonary edema, abruption placenta, thrombocytopenia, postpartum hemorrhage and stroke were recorded either from patient's medical chart or maternal discharge registration database ( $\log$ book). Maternal mortality, death of mother from admission until six weeks postpartum, was ascertained by physician's duty note and death summary including immediate causes of death for those who died in hospitals and from patient's caregiver via telephone interview. Length of hospital stay was a secondary outcome variable for this study. This was the duration of time that a patient was within the hospitals and it was obtained from a patient's discharge summary. For all, the time at which any event occurred was documented in terms of days from the patient medical chart in reference to the date of admission.

In this study, the occurrence of a seizure in association with preeclampsia was considered as eclampsia, ${ }^{12}$ while a blood pressure of $\geq 140 \mathrm{mmHg}$ for systolic or $\geq 90 \mathrm{mmHg}$ for diastolic accompanied by proteinuria that occurs after 20 weeks of gestation in previously normotensive woman is preeclampsia. $^{12}$ A proteinuria is the presence of $\geq 300 \mathrm{mg}$ of protein in a 24 -h urine specimen or $\geq 1+$ using a random urine dipstick evaluation and a 24h urine collection. ${ }^{13}$ For blood pressure $\geq 160 / 110 \mathrm{mmHg}$ accompanied by severe proteinuria $\geq 5 \mathrm{~g}$ of protein in a 24 $\mathrm{h}$ urine specimen or $\geq 3+$ using a random urine dipstick evaluation that occurred after 20 weeks of gestation in a woman with previously normal blood pressure, it was recorded as severe preeclampsia. ${ }^{17}$ Also, maternal morbidity record included at least one of the complications such as stroke, aspiration pneumonia, severe anemia, kidney failure, liver failure, HELLP syndrome (hemolysis, elevated liver enzymes and low platelets syndrome), puerperal sepsis, disseminated intravascular coagulation, and/or 
pulmonary edema. ${ }^{14}$ Death of a woman while she was pregnant or within six weeks of terminating the pregnancy related to or aggravated by the pregnancy or its management but not from accidental or incidental causes was taken as maternal mortality. ${ }^{14}$ The number of births after 28 weeks of pregnancy irrespective of the outcome was considered as parity. The separation of the placenta from the wall of the womb before birth was captured as placental abruption. ${ }^{15}$ We also considered puerperal sepsis for infection of the genital tract occurring at any time between the rupture of membranes or labor and six weeks period of postpartum in which two or more of the following are present: pelvic pains, fever $\left(\geq 38.5^{\circ} \mathrm{C}\right)$, abnormal vaginal smell or foul odor of discharge, delay in the rate of reduction of the size of the uterus $(<2 \mathrm{~cm}$ per day during the first eight days).

\section{Data Processing and Analysis}

Data were coded and entered into EpiData 3.1 and then exported to SPSS 21.0 for analysis. Descriptive analysis was performed and results were presented by tables and charts. Continuous variables were reported by mean and standard deviation. Cox regression model was used to compute hazard ratios and $95 \%$ confidence intervals to examine the individual relation between each predictor and maternal outcome (complication) during follow-up. Bivariate Cox regression was performed to identify variables with potential for association with outcome variable. Variables with $P$-value $<0.25$ in the bivariate regression were considered as candidates for multivariable regression. Multivariable Cox regression was performed to identify independent predictors of maternal complications and a $P$-value $<0.05$ was considered as a statistical significance.

\section{Results}

\section{Sociodemographic and Clinical \\ Characteristics}

From a total of 217 patients observed, 146 (67.3\%) of them were 20-34 years of age and $39.6 \%$ of them had become pregnant for the first time under the age of 18 . More than half of the women were illiterate (58.5\%), rural dwellers $(59 \%)$, and had seen their first menses at the age of 12 to 14 years $(59.4 \%)$, while just below half of them were nulliparous (49.3\%) and primigravida (48.4\%). Again, just below a quarter of the women had no antenatal care follow-up (22.6\%) (Table 1).
Over one-third of the patients were found to have leukocytosis $(38.7 \%)$, liver function derangements indicated by elevated AST (41.0\%), and elevated lactate dehydrogenase $(25.8 \%)$. But, slightly below one-quarter of the women had a raised serum creatinine level of above and equal to $2 \mathrm{mg} / \mathrm{dL}$ (23\%), while a far lower proportion of the patients had a low hemoglobin level of $11 \mathrm{mg} / \mathrm{dL}$ or below (17\%) (Table 2).

\section{Maternal Diagnosis and Anticonvulsants Used}

From the total of 217 patients, $176(81.1 \%)$ and 41 $(18.9 \%)$ of them were diagnosed with eclampsia and severe preeclampsia, respectively. The majority of the patients were given $\mathrm{MgSO}_{4}$ (78.8\%) at both settings, while only $(21.2 \%)$ of them were given diazepam. Diazepam was more commonly used by women at JUMC (30.4\%) than those at HFSUH (8.7\%) (Table 3).

\section{Maternal Treatment Outcomes}

From the total 217 women, nine $(4.2 \%)$ of them died and all of them were from the eclampsia cohort given a case fatality rate of $5.1 \%$. Six of the women who died were put on magnesium sulfate $\left(\mathrm{MgSO}_{4}\right)$ while three of them were given diazepam. The number of maternal mortality was higher at JUMC, six (4.8\%). The causes of maternal death reported were severe anemia, aspiration pneumonia, HELLP syndromes, acute kidney injury, and stroke (Table 4).

From the total of 217 women followed for around 2646 person-days, $174(80.2 \%)$ of them developed maternal complications throughout the course of the follow-up. The overall incidence rate of the maternal complication was 9.01 per 1000 person years (with 95\%CI of 7.7610.45). Of the total pregnant women who developed maternal complications, $80.7 \%$ were those who had been given magnesium sulfate while $78.3 \%$ were those who received diazepam. However, these maternal complications were more commonly observed in women from the eclampsia cohort $(84.7 \%)$ than those from the severe preeclampsia cohort (61\%). The most commonly occurring complications were aspiration pneumonia (22.9\%), severe anemia (18.4\%), and puerperal sepsis (13.2\%) (Table 4).

This study also revealed that seizure recurrence was observed among 35 (16.1\%) of the pregnant women admitted to both settings, a higher proportion of which from those women who were given diazepam (45.7\%) 
Table I Baseline Characteristics of Pregnant Women Admitted to Maternity Wards of JUMC and HFSUH from April I to October 30, $2019(\mathrm{~N}=217)$

\begin{tabular}{|c|c|c|c|c|c|c|}
\hline \multicolumn{2}{|l|}{ Characteristics } & \multirow{3}{*}{$\begin{array}{l}\text { Eclampsia }(\mathbf{N}=\mid \mathbf{7 6}) \\
\mathbf{N}(\%) \\
26(14.8) \\
122(69.3) \\
28(15.9)\end{array}$} & \multirow{3}{*}{$\begin{array}{l}\text { SPE }(\mathbf{n = 4}) \\
\mathbf{N}(\%) \\
5(\mid 2.2) \\
24(58.5) \\
12(29.3)\end{array}$} & \multicolumn{2}{|c|}{ Maternal Complication } & \multirow{3}{*}{$\begin{array}{l}P \text {-value } \\
0.265\end{array}$} \\
\hline & & & & \multirow{2}{*}{$\begin{array}{l}\text { Yes (\%) } \\
23(13.2) \\
115(66.1) \\
36(20.7)\end{array}$} & \multirow{2}{*}{$\begin{array}{l}\text { No (\%) } \\
8(18.6) \\
31(72.1) \\
4(9.3)\end{array}$} & \\
\hline Maternal age (year) & $\begin{array}{l}<20 \\
20-34 \\
\geq 35\end{array}$ & & & & & \\
\hline Educational status & $\begin{array}{l}\text { Illiterate } \\
\text { Primary } \\
\text { Secondary and above }\end{array}$ & $\begin{array}{l}101(57.4) \\
47(26.7) \\
28(15.9)\end{array}$ & $\begin{array}{l}26(63.4) \\
\text { II }(26.8) \\
4(98.8)\end{array}$ & $\begin{array}{l}106(60.9) \\
44(25.3) \\
24(13.8)\end{array}$ & $\begin{array}{l}21(48.8) \\
14(32.6) \\
8(18.6)\end{array}$ & 0.353 \\
\hline Residence & $\begin{array}{l}\text { Rural } \\
\text { Urban }\end{array}$ & $\begin{array}{l}100(56.8) \\
76(43.2)\end{array}$ & $\begin{array}{l}28(68.3) \\
13(31.7)\end{array}$ & $\begin{array}{l}104(59.8) \\
70(40.2)\end{array}$ & $\begin{array}{l}24(55.8) \\
19(44.2)\end{array}$ & 0.637 \\
\hline Blood pressure & $\begin{array}{l}\text { Elevated } \\
\text { Normal }\end{array}$ & $\begin{array}{l}142(80.7) \\
34(19.3)\end{array}$ & $\begin{array}{l}38(92.7) \\
3(7.3)\end{array}$ & $\begin{array}{l}146(83.9) \\
28(16.1)\end{array}$ & $\begin{array}{l}34(79.1) \\
9(20.9)\end{array}$ & 0.621 \\
\hline Age of menarche & $\begin{array}{l}12-14 \\
>14 \\
\text { Not known }\end{array}$ & $\begin{array}{l}106(60.2) \\
27(15.3) \\
43(24.4)\end{array}$ & $\begin{array}{l}23(56.1) \\
7(17.1) \\
I I(26.8)\end{array}$ & $\begin{array}{l}105(60.3) \\
24(13.8) \\
45(25.9)\end{array}$ & $\begin{array}{l}24(55.8) \\
10(23.3) \\
9(20.9)\end{array}$ & 0.297 \\
\hline Age at first pregnancy & $\begin{array}{l}<18 \\
\geq 18 \\
\text { Not known }\end{array}$ & $\begin{array}{l}68(38.6) \\
97(55.1) \\
I I(6.2)\end{array}$ & $\begin{array}{l}18(43.9) \\
17(41.5) \\
6(14.6)\end{array}$ & $\begin{array}{l}64(36.8) \\
97(55.7) \\
13(7.5)\end{array}$ & $\begin{array}{l}22(51.2) \\
17(39.5) \\
4(9.3)\end{array}$ & 0.159 \\
\hline Maternal parity & $\begin{array}{l}\text { Nulliparous } \\
\text { Multiparous } \\
\text { Primiparous }\end{array}$ & $\begin{array}{l}92(52.3) \\
51(29) \\
33(18.2)\end{array}$ & $\begin{array}{l}15(36.6) \\
20(48.8) \\
6(14.6)\end{array}$ & $\begin{array}{l}86(49.4) \\
55(31.6) \\
33(19)\end{array}$ & $\begin{array}{l}21(48.8) \\
16(37.2) \\
6(14)\end{array}$ & 0.665 \\
\hline Maternal gravidity & $\begin{array}{l}\text { Primigravida } \\
\text { Multigravida }\end{array}$ & $\begin{array}{l}90(5 I .1) \\
86(48.9)\end{array}$ & $\begin{array}{l}15(36.6) \\
26(63.4)\end{array}$ & $\begin{array}{l}83(47.7) \\
91(52.3)\end{array}$ & $\begin{array}{l}22(51.2) \\
21(48.8)\end{array}$ & 0.684 \\
\hline Pregnancy multiplicity & $\begin{array}{l}\text { Singleton } \\
\text { Twin }\end{array}$ & $\begin{array}{l}155(88.1) \\
21 \text { (II.9) }\end{array}$ & $\begin{array}{l}34 \text { (82.9) } \\
7(17.1)\end{array}$ & $\begin{array}{l}\text { I54 (88.5) } \\
20(1 \mid .5)\end{array}$ & $\begin{array}{l}35(81.4) \\
8(18.6)\end{array}$ & 0.213 \\
\hline Duration of labor (hours) & $\begin{array}{l}<24 \\
\geq 24\end{array}$ & $\begin{array}{l}148(84.1) \\
28(I 5.9)\end{array}$ & $\begin{array}{l}32(78) \\
9(22)\end{array}$ & $\begin{array}{l}142(8 \mid .6) \\
32(18.4)\end{array}$ & $\begin{array}{l}38(88.4) \\
5(11.6)\end{array}$ & 0.291 \\
\hline Route of delivery & $\begin{array}{l}\text { SVD } \\
C / S\end{array}$ & $\begin{array}{l}104(59.1) \\
72(40.9)\end{array}$ & $\begin{array}{l}24(58.5) \\
17(4 \mid .5)\end{array}$ & $\begin{array}{l}100(57.5) \\
74(42.5)\end{array}$ & $\begin{array}{l}28(65.1) \\
15(34.9)\end{array}$ & 0.361 \\
\hline Gestational age (weeks) & $\begin{array}{l}<37 \\
37-41 \\
\text { Not stated }\end{array}$ & $\begin{array}{l}49(27.8) \\
125(7 I) \\
2(I . I)\end{array}$ & $\begin{array}{l}16(39) \\
25(61) \\
0(-)\end{array}$ & $\begin{array}{l}52(29.9) \\
120(69) \\
2(1.1)\end{array}$ & $\begin{array}{l}13(30.2) \\
30(69.8) \\
0(-)\end{array}$ & 0.779 \\
\hline ANC follow-up & $\begin{array}{l}\text { Yes } \\
\text { No }\end{array}$ & $\begin{array}{l}\text { I } 34(76.1) \\
42(23.9)\end{array}$ & $\begin{array}{l}34(82.9) \\
7(17.1)\end{array}$ & $\begin{array}{l}129(74.1) \\
45(25.9)\end{array}$ & $\begin{array}{l}39(90.7) \\
4(9.3)\end{array}$ & 0.02 \\
\hline
\end{tabular}

rather than magnesium sulfate $(8.2 \%)$. From the perspective of the settings, a higher seizure recurrence rate was observed at JUMC (19.2\%) than at HFSUH (11.0\%) (Table 4).

The Kaplan-Meier survival curve showed that there were significant difference in probability of survival for women with eclampsia and severe preeclampsia. Accordingly, cumulative survival of pregnant women with complications at about 40 days of follow-up for eclamptic and severe preeclamptic women was estimated to be around $10 \%$ and $40 \%$, respectively ( $P=0.0001)$ (Figure 1 ).

However, Kaplan-Meier survival curve showed that there were no significant difference in survival curve of women with maternal complications by treatment with diazepam and magnesium sulphate. Women who have been given magnesium sulphate had an estimated median survival time of two days while those given diazepam were three days $(P=0.537)$ (Figure 2). 
Table 2 Laboratory Reports of Pregnant Women Admitted to Maternity Ward of JUMC and HFSUH from April I to October 30, $2019(\mathrm{~N}=217)$

\begin{tabular}{|c|c|c|c|c|c|}
\hline \multicolumn{2}{|l|}{ Laboratory Values } & \multirow[t]{2}{*}{ Category } & \multicolumn{2}{|c|}{ Maternal Complication } & \multirow[t]{2}{*}{$P$-value } \\
\hline & & & Yes (\%) & No (\%) & \\
\hline \multirow[t]{3}{*}{ Complete blood count } & WBC (cells $\left./ \mathrm{mm}^{3}\right)$ & $\begin{array}{l}\text { Normal }\left(4.4-11.5 \times 10^{3}\right) \\
\text { Elevated }\left(\geq 12 \times 10^{3}\right)\end{array}$ & $\begin{array}{l}97(55.7) \\
77(44.3)\end{array}$ & $\begin{array}{l}36(83.7) \\
7(16.3)\end{array}$ & 0.001 \\
\hline & Hemoglobin $(\mathrm{g} / \mathrm{dL})$ & $\begin{array}{l}\text { Normal }(I I-14) \\
\text { Low }(\leq 11)\end{array}$ & $\begin{array}{l}144(82.8) \\
30(17.2)\end{array}$ & $\begin{array}{l}40(93) \\
3(7)\end{array}$ & 0.093 \\
\hline & Platelets (cells $/ \mathrm{mm}^{3}$ ) & $\begin{array}{l}\text { Normal }(150-450) \\
\text { Low }(<150)\end{array}$ & $\begin{array}{l}109(62.6) \\
65(37.4)\end{array}$ & $\begin{array}{l}40(93) \\
3(7)\end{array}$ & 0.0001 \\
\hline \multirow[t]{3}{*}{ LFT } & AST (U/L) & $\begin{array}{l}\text { Normal }(0-42) \\
\text { Elevated }(\geq 2 \times \cup N L)\end{array}$ & $\begin{array}{l}94(54) \\
80(46)\end{array}$ & $\begin{array}{l}34(79.1) \\
9(20.9)\end{array}$ & 0.003 \\
\hline & ALT (U/L) & $\begin{array}{l}\text { Normal }(0-35) \\
\text { Elevated }(\geq 2 \times \cup N L)\end{array}$ & $\begin{array}{l}110(63.2) \\
64(36.8)\end{array}$ & $\begin{array}{l}35(81.4) \\
8(18.6)\end{array}$ & 0.023 \\
\hline & LDH (U/L) & $\begin{array}{l}\text { Normal }(100-210) \\
\text { Elevated }(\geq 2 \times \cup N L)\end{array}$ & $\begin{array}{l}\text { I24 (7I.3) } \\
50(28.7)\end{array}$ & $\begin{array}{l}37(86) \\
6(14)\end{array}$ & 0.047 \\
\hline \multirow[t]{2}{*}{ RFT } & $\mathrm{SrCr}(\mathrm{mg} / \mathrm{dL})$ & $\begin{array}{l}\text { Normal }(0.7-1.5) \\
\text { Elevated }(\geq 2)\end{array}$ & $\begin{array}{l}\text { I } 30(75.1) \\
44(24.9)\end{array}$ & $\begin{array}{l}37(86) \\
6(14)\end{array}$ & 0.127 \\
\hline & BUN (mg/dL) & $\begin{array}{l}\text { Normal }(8-20) \\
\text { Elevated }(\geq 20)\end{array}$ & $\begin{array}{l}112(64.7) \\
62(35.3)\end{array}$ & $\begin{array}{l}27(62.8) \\
16(37.2)\end{array}$ & 0.811 \\
\hline
\end{tabular}

Abbreviations: ALT, alanine aminotransferase; AST, aspartate aminotransferase; BUN, blood urea nitrogen; LDH, lactate dehydrogenase; LFT, liver function test; RFT, renal function test; SrCr, serum creatinine; WBC, white blood cells; SPE, severe preeclampsia.

\section{Length of Hospital Stay}

The mean length of hospital stay was $7.2 \mathrm{SD} \pm 4.7$. The longer duration of hospital stay was seen in women with eclampsia, $86(85.1 \%)$ than those of severe preeclampsia, $15(14.9 \%)$ although this longer stay was observed from those women who have been provided magnesium sulfate than diazepam, $(82.2 \%$ vs $17.8 \%)$.

\section{Factors Associated with Maternal}

\section{Complications}

In this study, binary Cox regression analysis showed that factors such as multiplicity of pregnancy, Glasgow coma scale, maternal history of previous preeclampsia or eclampsia, antenatal care follow-up, seizure recurrence, type of maternal diagnosis, educational status, maternal age, elevated white blood cells, low platelets, and elevated serum creatinine and liver enzyme levels were statistically related with significant association to maternal complications. However, after adjusting for cofounders in multivariable Cox regression analysis, only variables including lack of antenatal care follow-up (AHR: 1.75; 95\%CI: $1.22-2.51 ; P=0.002)$, eclampsia as type of maternal diagnosis (AHR: $1.98 ; 95 \% \mathrm{CI}: 1.28-3.06 ; P=0.002$ ), maternal age between 20 and 34 years (AHR: 0.61 ; 95\%CI: $0.41-$

Table 3 Types of Maternal Diagnosis and Anticonvulsants Used Among Pregnant Women Admitted to Maternity Wards of JUMC and HFSUH from April I to October 30, 2019

\begin{tabular}{|l|l|c|c|c|}
\hline Variable & Category & Total (N=2 I7) & JUMC (N= I25) & HFSUH (N=92) \\
\cline { 3 - 5 } & & $\mathbf{N}(\%)$ & $\mathbf{N}(\%)$ & $\mathbf{N}(\%)$ \\
\hline Maternal diagnosis & Eclampsia & $176(81.1)$ & $92(73.6)$ & $84(91.3)$ \\
& $\mathrm{SPE}$ & $41(18.9)$ & $33(26.4)$ & $8(8.7)$ \\
\hline \multirow{2}{*}{ Anticonvulsants } & $\mathrm{MgSO}_{4}$ & $171(78.8)$ & $87(69.6)$ & $84(91.3)$ \\
& Diazepam & $46(21.2)$ & $38(30.4)$ & $8(8.7)$ \\
\hline
\end{tabular}


Table 4 Maternal Treatment Outcomes for Women with Eclampsia and Severe Preeclampsia Admitted to Maternity Wards of JUMC and HFSUH from April I to October 30, 2019

\begin{tabular}{|c|c|c|c|c|c|c|c|}
\hline \multicolumn{2}{|l|}{ Treatment Outcomes } & \multicolumn{2}{|c|}{ Diagnosis } & \multicolumn{2}{|c|}{ Anticonvulsants } & \multicolumn{2}{|c|}{ Hospitals } \\
\hline & & Eclampsia (\%) & SPE (\%) & $\mathrm{MgSO}_{4}(\%)$ & Diazepam (\%) & JUMC (\%) & HFSUH (\%) \\
\hline \multirow[t]{2}{*}{ Maternal complication } & Yes & 149 (84.7) & $25(6 \mathrm{I})$ & I 38 (80.7) & $36(78.3)$ & $97(77.6)$ & $77(83.7)$ \\
\hline & No & $27(15.3)$ & $16(39)$ & $33(19.3)$ & $10(21.7)$ & $28(22.4)$ & $15(16.3)$ \\
\hline \multirow[t]{2}{*}{ Maternal mortality } & Yes & $9(5.1)$ & $0(-)$ & $6(3.5)$ & $3(6.5)$ & $6(4.8)$ & $3(3.3)$ \\
\hline & No & $167(94.9)$ & $4 I(100)$ & $165(96.5)$ & $43(19.8)$ & $119(95.2)$ & $89(96.7)$ \\
\hline \multirow[t]{2}{*}{ Seizure recurrence } & Yes & $35(19.9)$ & $0(-)$ & $14(8.2)$ & $21(45.7)$ & $24(19.2)$ & II (I2) \\
\hline & No & $|4|(80.1)$ & $4 I(I 00)$ & I57 (9|.8) & $25(54.3)$ & I0I (80.8) & $81(88)$ \\
\hline \multicolumn{8}{|c|}{ Types of maternal complications } \\
\hline \multicolumn{2}{|l|}{ Aspiration pneumonia } & $39(26.2)$ & I (4) & $35(25.4)$ & $5(14)$ & $12(12.4)$ & $28(36.4)$ \\
\hline \multicolumn{2}{|l|}{ Severe anemia } & $23(15.4)$ & $9(36)$ & $24(17.4)$ & $8(22.2)$ & $21(21.7)$ & II (I4.3) \\
\hline \multicolumn{2}{|l|}{ AP and HELLP } & $27(18.1)$ & I (4) & $25(18.1)$ & $3(8.3)$ & $7(7.2)$ & $21(27.3)$ \\
\hline \multicolumn{2}{|l|}{ Puerperal sepsis } & $16(10.7)$ & $7(28)$ & $16(11.6)$ & $7(19.4)$ & $17(17.5)$ & $6(7.8)$ \\
\hline \multicolumn{2}{|l|}{ HELLP syndromes } & $19(12.8)$ & $2(8)$ & $18(13)$ & $3(8.3)$ & $15(15.5)$ & $6(7.8)$ \\
\hline \multicolumn{2}{|l|}{ AKI } & II (7.4) & I (4) & $9(6.5)$ & $3(8.3)$ & $10(10.3)$ & $2(2.6)$ \\
\hline \multicolumn{2}{|l|}{ DIC } & $9(6.1)$ & $0(0)$ & $5(3.6)$ & $4(I I . I)$ & $9(9.3)$ & $0(0)$ \\
\hline \multicolumn{2}{|l|}{ PE } & $2(1.3)$ & $3(12)$ & $3(2.2)$ & $2(5.6)$ & $5(5.2)$ & $0(0)$ \\
\hline \multicolumn{2}{|l|}{ Others $\mathrm{a}^{\mathrm{a}}$} & $3(2)$ & I (4) & $3(2.2)$ & $\mathrm{I}(2.8)$ & $\mathrm{I}(\mathrm{I})$ & $3(3.8)$ \\
\hline
\end{tabular}

Note: ${ }^{a}$ Stroke, thrombocytopenia, and abruption placenta.

Abbreviations: AKI, acute kidney injury; AP, aspiration pneumonia; DIC, disseminated intravascular coagulation; HELLP, hemolysis, elevated liver enzymes, lower platelet; HFSUH, Hiwot Fana Specialized University Hospital; JUMC, Jimma University Medical Center; PE, pulmonary edema.

$0.90 ; P=0.01$ ), maternal leukocytosis (AHR: $1.53 ; 95 \% \mathrm{CI}$ :

$1.12-2.09 ; P=0.008)$ and elevated serum creatinine levels (AHR: 1.51 ; 95\%CI: $1.05-2.17 ; P=0.02$ ) were revealed as independent determinants of maternal complications (Table 5).

\section{Discussion}

Eclampsia, a complication usually following hypertensive diseases of pregnancy, remains a cause of maternal morbidity and mortality. The present study witnessed that the majority $(81.1 \%)$ of women were diagnosed with

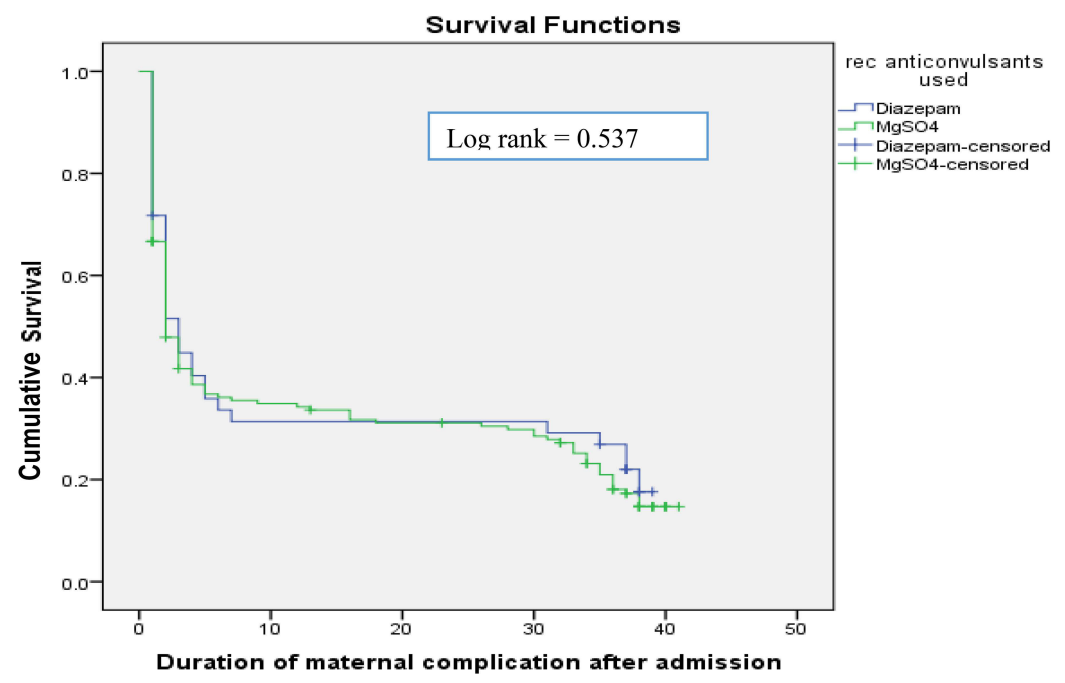

Figure I Kaplan-Meier survival curve of maternal complications for maternal diagnosis among pregnant women admitted maternity wards of JUMC and HFSUH from April I to October 30, 2019. 


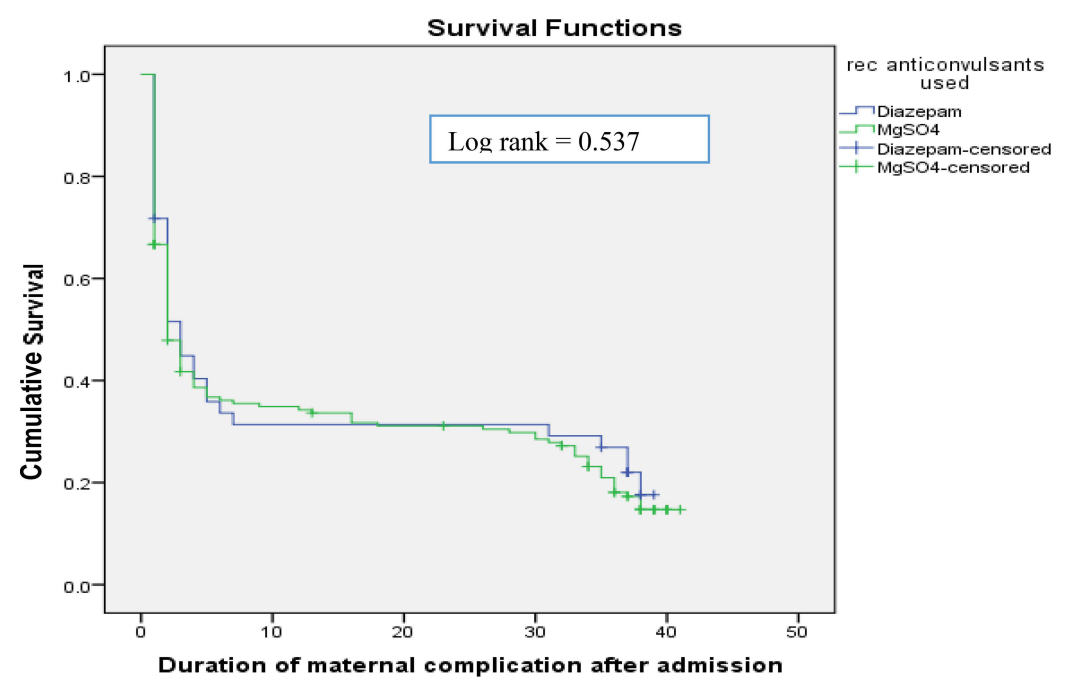

Figure 2 Kaplan-Meier survival curve of maternal complications by anticonvulsants used among pregnant women admitted maternity wards of JUMC and HFSUH from April I to October 30, 2019.

eclampsia and about three-quarters of women were given magnesium sulfate.

In present study, the maternal mortality rate was $4.2 \%$ and all of them were attributed to eclampsia given the case fatality rate of $5.1 \%$. This finding was in line with previous studies which reported a case fatality rate of eclampsia at JUMC $4.76 \%$, a nationwide maternal mortality trend analysis of $6.5 \%, 5.5 \%$ in Nigeria, $4 \%$ in India, and 5.3\% in Nepal. ${ }^{11,16-19}$ However, a lower figure was reported in Egypt where the case fatality rate of eclampsia was $1.6 \%$. This discrepancy might be due to facility difference and/or high ANC follow-up in Egypt. ${ }^{20}$ Higher eclampsia fatality rate was also reported in Nigeria, $7.5 \%$ and Ethiopia, $11 \%$. These might be justified with the retrospective nature of their study designs and only eclamptic cases of all studied patients included at those settings. ${ }^{21,22}$ The fact that maternal mortality was lower among groups given magnesium sulphate instead of diazepam was also supported by our study as higher mortality was seen among women who were given diazepam $(6.5 \%)$ than those given magnesium sulphate $(3.5 \%))^{3,9,10,23}$ Our study also showed that the causes of maternal mortality were severe anemia, coexistence of aspiration pneumonia and HELLP syndromes, acute kidney injury, stroke and aspiration pneumonia which was consistent with reports of different studies. $^{18,21,24,25}$

Regarding complications, this study revealed that the majority $(80.2 \%)$ of the women in the study developed maternal complications throughout the course of follow- up. This finding was in line with research done in Tanzania and Nigeria where the proportions of maternal complication were found to be $75 \%{ }^{26}$ and $79.3 \%,{ }^{27}$ respectively. However, lower maternal complications were reported from Nepal (20\%), South Asia (38\%), and South Nigeria $(37.7 \%)$ which could be reasoned as better management of the cases in those countries. ${ }^{19,21,28}$ Similar studies conducted in Ethiopia also reported lower maternal complication rate in Addis Ababa $(35-36 \%)^{29,30}$ and Hidar 11 hospitals $(30.8 \%))^{31}$ This discrepancy may be related to our study factors such as enrollment of higher number of eclampsia cases than preeclampsia, low rate of ANC follow-up, and greater number of patients participating from rural dwellers compared to these similar settings.

In this study, the most commonly occurring complications were aspiration pneumonia $(22.9 \%)$, severe anemia (18.4\%), coexistence of aspiration pneumonia and HELLP syndromes $(16.1 \%)$, puerperal sepsis $(13.2 \%)$, and acute kidney injury (6.9\%). This finding was in line with studies conducted in Egypt where HELLP syndrome was 15.6\%, and renal impairment was $7.2 \%{ }^{20}$ and in Zimbabwe where HELLP syndromes accounted for $9.1 \% .^{32}$ These slight differences might be due to the usually stated predominance of infectious causes of complications such as aspiration pneumonia and puerperal sepsis in relatively resource limited settings as in the current study. Besides, an Ethiopian study in Gandhi Memorial Hospital showed HELLP syndrome (14\%), oliguria (12.5\%), and renal failure $(6.5 \%)$ as the most common maternal complications. ${ }^{30}$ A similar study done in Addis Ababa also revealed that 
Table 5 Factors Associated with Maternal Complications Among Pregnant Women Admitted to Maternity Wards of JUMC and HFSUH from April I to October 30, 2019

\begin{tabular}{|c|c|c|c|c|c|c|c|}
\hline \multirow[t]{2}{*}{ Variables } & \multirow[t]{2}{*}{ Category } & \multicolumn{2}{|c|}{ Maternal Complications } & \multirow[t]{2}{*}{$P$-value } & \multirow[t]{2}{*}{ CHR (95\%Cl) } & \multirow[t]{2}{*}{$P$-value } & \multirow[t]{2}{*}{ AHR $(95 \% \mathrm{Cl})$} \\
\hline & & Yes (\%) & No (\%) & & & & \\
\hline \multirow[t]{2}{*}{ ANC follow-up } & Yes & $129(74.1)$ & $39(90.7)$ & I & & I & \\
\hline & No & $45(25.9)$ & $4(9.3)$ & 0.004 & $1.66(1.18-2.34)$ & 0.002 & $1.75(1.22-2.5 \mathrm{I})$ \\
\hline \multirow[t]{2}{*}{ WBC } & Elevated & $77(44.3)$ & $7(16.3)$ & 0.003 & $1.57(1.16-2.13)$ & 0.008 & $1.53(1.12-2.09)$ \\
\hline & Normal & 97 (55.7) & $36(83.7)$ & 1 & & I & \\
\hline \multirow[t]{2}{*}{$\mathrm{SrCr}$} & Elevated & $44(25.3)$ & $6(13.9)$ & 0.096 & $1.34(0.95-1.89)$ & 0.025 & $1.51(1.05-2.17)$ \\
\hline & Normal & $130(74.7)$ & $37(86.1)$ & 1 & & 1 & \\
\hline \multirow[t]{2}{*}{ Diagnosis } & Eclampsia & $149(85.6)$ & $27(62.8)$ & 0.001 & $2.06(1.35-3.16)$ & 0.002 & $1.98(1.28-3.06)$ \\
\hline & SPE & $25(14.4)$ & $16(37.2)$ & 1 & & I & \\
\hline \multirow[t]{3}{*}{ Age (years) } & $<20$ & $23(13.2)$ & $8(18.6)$ & 0.153 & $0.68(0.40-1.15)$ & 0.14 & $0.67(0.39-1.14)$ \\
\hline & $20-34$ & II5 (66.I) & $31(72.1)$ & 0.076 & $0.71(0.49-1.04)$ & 0.013 & $0.6 \mathrm{I}(0.4 \mathrm{I}-0.90)$ \\
\hline & $\geq 35$ & $36(20.7)$ & $4(9.3)$ & 1 & & I & \\
\hline
\end{tabular}

Notes: All the above laboratory investigations were those done at admission. I= reference category. Elevated $\mathrm{SrCr}(\geq 2 \mathrm{mg} / \mathrm{dL}) ; \mathrm{Elevated} \mathrm{WBC}\left(\geq 12 \times 10^{3}\right.$ cells $\left./ \mathrm{mm}^{3}\right)$. Abbreviations: AHR, adjusted hazard ratio; ANC, antenatal care; $\mathrm{CHR}$, crude hazard ratio; $\mathrm{Cl}$, confidence interval; SPE. severe preeclampsia.

HELLP syndrome (39.5\%), aspiration pneumonia $(17.5 \%)$, pulmonary edema $(17.5 \%)$, and abruption placenta $(15.3 \%)$ were the most frequent complications, ${ }^{29}$ which were also in line with the present study regardless of a little different sequence of the common maternal complications. It might be partly due the higher seizure recurrence rate that could lead to aspiration pneumonia as the most frequent complication even at the expense of higher magnesium sulfate usage in the present study.

The fact that major maternal complications are mainly from eclampsia rather than severe preeclamptic women also held true in this study, $84.7 \%$ and $61 \%$, respectively. Nevertheless, in our study slightly more women who had been given magnesium sulfate $(80.7 \%)$ developed complications than those given diazepam (78.3\%). This was a contrasting finding to results of different studies that supported patients treated with magnesium sulfate were more favorable for maternal outcome than those given diazepam. ${ }^{11,17,20,21,30}$ This may probably be due to the large number of women who convulsed before the magnesium sulfate had been initiated and there was uncertainty whether the current hospitals did really follow either the setting or the national protocol of magnesium sulfate administration or not.

Looking at the factors by the Cox regression analysis in the present study showed that absence of antenatal care (AHR: 1.75), being eclampsia case (AHR: 1.98), elevated WBC (AHR: 1.6), and raised serum creatinine levels as independent determinants of maternal complications whereas being in the age group of 20-34 years (AHR: 0.60) was about $40 \%$ less likely to develop maternal complications compared to women aged at least 35 years.

Women with eclampsia had 1.98 times higher risk of developing maternal complications compared to those women with severe preeclampsia which was in agreement with studies conducted in Nigeria, Uganda, and Ethiopia. ${ }^{16,33,34}$ Again, women who did not have antenatal care follow-up developed maternal complications by 1.75fold which was consistent with studies done in Egypt and Ethiopia where poor antenatal care service were identified as a major predictor of maternal complication. ${ }^{20,34}$ The present study also found that elevated maternal serum creatinine at admission was linked with increased maternal complications by $50 \%$ compared with normal values. This finding was in line with a study done in the southern part of the country. ${ }^{34}$ Besides, baseline leukocytosis predicted about $53 \%$ increased risk of maternal complications than normal white blood cells. This might be related to the high incidence of infectious maternal complications in the current study and the fact that leukocytosis is considered to be evidence of an increased inflammatory response during normal pregnancy and in preeclampsia. ${ }^{35}$

Despite a prospective follow-up and tertiary settings selected for the study, it was not without limitations. A nonrandom selection of the only two settings from the country might limit its representativeness for all hospitals 
in the nation. Besides, the small and unequal sample size with regard to the type of maternal diagnoses and anticonvulsants utilized could have underpowered the study and underestimated the intended results. Finally, longterm maternal complications beyond six weeks of postpartum period were not addressed due to time limitation for the study. Therefore, interpretations of these findings should be seen in the context of the aforementioned limitations.

\section{Conclusion}

We found eclampsia as a common and serious problem that leads to both maternal complications and mortality in the face of more practice with magnesium sulphate use. The majority of patients developed maternal complications and the most common complications were aspiration pneumonia followed by severe anemia, and HELLP syndromes. Independent predictors of increased maternal complications were cases of eclampsia, absence of ANC follow-up, elevated baseline WBC and serum creatinine, but the complications were decreased in the group of women aged 20-34 years. As far as our results are concerned, we suggest productive work on promoting ANC follow-up, early detection of eclampsia and appropriate management of the complications. Again, revising the magnesium sulfate administration protocol has to be considered for the optimal prevention and treatment of eclamptic seizures. Finally, since an outcome of eclampsia is unfavorable once it occurrs, special emphasis on strategies that prevent the occurrence of it should also be sought.

\section{Data Sharing Statement}

All relevant data were included in the manuscript.

\section{Ethical Consideration}

Ethical clearance and study approval was obtained from the Institutional Review Board of Jimma University, Institute of Health (Reference number: IHRPGD/586/ 2019). Verbal and written consents were obtained from all study participants before enrolling them to the study. The data from the case records and interviews were handled with strong confidentiality and we ensured neither the case records nor the data abstracted were used for any purpose other than the current research.

All participants were informed about the purpose of the study, and that it was conducted in accordance with the Declaration of Helsinki.

\section{Author Contributions}

All authors contributed to data analysis, drafting or revising the article, have agreed on the journal to which the article was submitted, gave final approval of the version to be published, and agree to be accountable for all aspects of the work.

\section{Funding}

The research was funded by Jimma University.

\section{Disclosure}

The authors report no conflicts of interest in this work.

\section{References}

1. Upadya M, Rao ST. Hypertensive disorders in pregnancy. Indian J Anaesth. 2018;62(9):675-681. doi:10.1016/j.cqn.2013.04.001

2. Ye C, Ruan Y, Zou L, et al. The 2011 survey on hypertensive disorders of pregnancy (HDP) in China: prevalence, risk factors, complications, pregnancy and perinatal outcomes. PLoS One. 2014;9(6):e100180.

3. Abalos E, Cuesta C, Carroli G, et al. Pre-eclampsia, eclampsia and adverse maternal and perinatal outcomes: a secondary analysis of the World Health Organization Multicountry Survey on Maternal and Newborn Health. BJOG. 2014;121(Suppl):14-24. doi:10.1111/14710528.12629

4. Duley L. The global impact of pre-eclampsia and eclampsia. Semin Perinatol. 2009;33(3):130-137. doi:10.1053/j.semperi.2009.02.010

5. Berhe AK, Kassa GM, Fekadu GA, Muche AA. Prevalence of hypertensive disorders of pregnancy in Ethiopia: a systemic review and meta-analysis. BMC Pregnancy Childbirth. 2018;18(34):1-11. doi:10.1186/s12884-018-1667-7

6. Wolde Z, Hailemariam Segni MW. Hypertensive disorders of pregnancy in jimma university specialized hospital. Ethiop J Health Sci. 2011;21(3):147-154.

7. Gaym A, Bailey P, Pearson L, Admasu K, Gebrehiwot Y. Disease burden due to pre-eclampsia/eclampsia and the Ethiopian health system's response. Int J Gynecol Obstet. 2011;115(1):112-116. doi:10.1016/j.ijgo.2011.07.012

8. Clinical treatment guidelines - gynecology and obstetrics. Kigali: Ministry of Health; 2012:1-188. Available from: https://www.moh. gov.rw/fileadmin/user_upload/Moh/Publications/Guidelines_ Protocols/Clinical_Protocols/OBS_Gyn_last-version.pdf.

9. Duley L, Am G, Chou D. Magnesium sulphate versus lytic cocktail for eclampsia. Cochrane Database Syst Rev. 2010;2010(9): CD002960.

10. Kassie GM, Negussie D, Hussien J. Perinatal outcomes of magnesium sulphate and diazepam use in severe pre-eclamptic and eclamptic mothers, Jimma University Specialized Hospital, Southwest Ethiopia. Int J Sci Basic Appl Res. 2014;13(1):426-436.

11. Kassie GM, Negussie D, Ahmed JH. Maternal outcomes of magnesium sulphate and diazepam use in women with severe pre-eclampsia and eclampsia in Ethiopia. Pharm Pract. 2014;12(2):400.

12. WHO recommendations for prevention and treatment of pre-eclampsia and eclampsia: implications and actions. WHO; 2013. Available from: https://apps.who.int/iris/bitstream/handle/ 10665/119627/WHO_RHR_14.17_eng.pdf.

13. Gillon TER, Pels A, Von Dadelszen P, Macdonell K. Hypertensive disorders of pregnancy: a systematic review of international clinical practice guidelines. PLoS One. 2014;9:e113715. 
14. Duley L, Meher S, Jones L. Drugs for treatment of very high blood pressure during pregnancy (Review). Cochrane Database Syst Rev. 2013;7:1-161.

15. Brown MA, Magee LA, Kenny LC, et al. Hypertensive Disorders of Pregnancy: ISSHP classification, diagnosis, and management recommendations for international practice. Hypertension. 2018;72:24-43.

16. Charles A, Victor P, Jonathan K, Ishaya P. Eclampsia and pregnancy outcome at Jos University teaching hospital, Jos, Plateau State, Nigeria. Int J Gynaecol Obstet. 2017;5(4):46-49. doi:10.11648/j. jgo.20170504.11

17. Ahmed A. Maternal mortality trend in Ethiopia. Ethiop J Health Dev. 2010;24(Special Issue 1):115-122.

18. Sunita TH, Desai RM. Eclampsia in a teaching hospital: incidence, clinical profile and response to magnesium sulphate by Zuspan's regimen. IOSR J Dent Med Sci. 2013;4(2):1-5. doi:10.9790/0853-0420105

19. Ghimire S. Eclampsia: feto-Maternal Outcomes in A Tertiary Care Centre in Eastern. J Nepal Med Assoc. 2016;54(201):24-28. doi:10.31729/jnma.2812

20. Mahran A, Fares H, Elkhateeb R, et al. Risk factors and outcome of patients with eclampsia at a tertiary hospital in Egypt. BMC Pregnancy Childbirth. 2017;17:1-7. doi:10.1186/s12884-017-1619-7

21. Eke AC, Ezebialu IU, Okafor C. Presentation and outcome of eclampsia at a tertiary center in South East Nigeria - a 6-year review. Hypertens Pregnancy. 2011;30(1):125-132. doi:10.3109/ 10641955.2010 .525283

22. Gudu W, Bekele D. A prospective review of eclampsia at a Regional Hospital, Eastern Ethiopia: incidence, clinical correlates, management and pregnancy outcome. Ethiop Med J. 2018;56(2):125-132.

23. Regmi MC, Aggrawal A, Pradhan T, Rijal P, Subedi A, Uprety D. Loading dose versus standard regimen of magnesium sulphate in eclampsia - a randomized trial. Nepal Med Coll J. 2010;12(4):244-247.

24. Bhalerao A, Kulkarni S, Ghike S, Kawthalkar A, Joshi S, Somalwar S. Eclampsia: maternal and Fetal Outcome. J South Asian Feder Obstet Gynaecol. 2013;5(1):19-21. doi:10.5005/jpjournals-10006-1212

25. Abd DEM, Aal E, Shahin AY. International Journal of Gynecology and Obstetrics Management of eclampsia at Assiut University Hospital, Egypt. Int J Gynecol Obstet. 2012;116(3):232-236. doi:10.1016/j.ijgo.2011.10.018
26. Ndaboine EM, Kihunrwa A, Rumanyika R, Im HB, Anthony N. Maternal and perinatal outcomes among eclamptic patients admitted to Bugando Medical Centre, Mwanza, Tanzania. Afr J Reprod Health. 2012;16(1):35-41.

27. Adamu AN, Ekele BA, Ahmed Y, Mohammed BA, Isezuo SA, Abdullahi AA. Pregnancy outcome in women with eclampsia at a tertiary centre in northern Nigeria. Afr $J$ Med Med Sci. 2012;41:211-219.

28. Kaur P. A clinical study on eclampsia in a referral hospital. J South Asian Feder Obstet Gynaecol. 2012;4(2):113-115. doi:10.5005/jpjournals-10006-1188

29. Wagnew M, Dessalegn M, Worku A, Nyagero J. Trends of preeclampsia/eclampsia and maternal and neonatal outcomes among women delivering in Addis Ababa selected government hospitals, Ethiopia: a retrospective cross-sectional study. Pan Afr Med J. 2016;363(2):1-6.

30. Mohammedseid SI, Megersa TN, Kumbi S, Biset M. Maternal outcomes of pre-eclampsia in an Ethiopian Gynecologic Hospital. Ann Med Health Sci Res. 2017;7:16-21.

31. Cherie N, Mohammed A. The maternal outcomes and its determinants among pregnant women complicated by severe preeclampsia at Hidar 11 hospital. Int Res J Public Health. 2018;2(24):1-9.

32. Ngwenya S. Severe preeclampsia and eclampsia: incidence, complications, and perinatal outcomes at a low-resource setting, Mpilo Central Hospital. Int $J$ Women's Health. 2017;9:353-357. doi:10.2147/IJWH.S131934

33. Nakimuli A, Nakubulwa S, Kakaire O, et al. The burden of maternal morbidity and mortality attributable to hypertensive disorders in pregnancy. BMC Pregnancy Childbirth. 2016;16(205):1-8. doi:10.1186/s12884-016-1001-1

34. Berhan Y, Endeshaw G. Maternal mortality predictors in women with hypertensive disorders of pregnancy: retrospective Cohort Study. Ethiop J Health Sci. 2015;25(1):89-99. doi:10.4314/ejhs.v25i1.12

35. Canzoneri BJ, Lewis DF, Groome L, Wang Y. Increased neutrophil numbers account for leukocytosis in women with preeclampsia. Am $J$ Perinatol. 2009;26(10):729-732. doi:10.1055/s-0029-1223285
International Journal of Women's Health

\section{Publish your work in this journal}

The International Journal of Women's Health is an international, peerreviewed open-access journal publishing original research, reports, editorials, reviews and commentaries on all aspects of women's healthcare including gynecology, obstetrics, and breast cancer. The manuscript management system is completely online and includes a very quick and fair peer-review system, which is all easy to use. Visit http://www.dovepress.com/testimonials.php to read real quotes from published authors. 